Supporting Information

\title{
A Visible Light Responsive ON-OFF Polymeric Photoswitch for the Colorimetric Detection of Nerve Agent Mimics in Solution and in the Vapor Phase
}

\author{
A. Balamurugan and Hyung-il Lee* \\ Department of Chemistry, University of Ulsan, Ulsan, 680-749, Republic of Korea
}

* Corresponding Author: sims0904@ulsan.ac.kr 

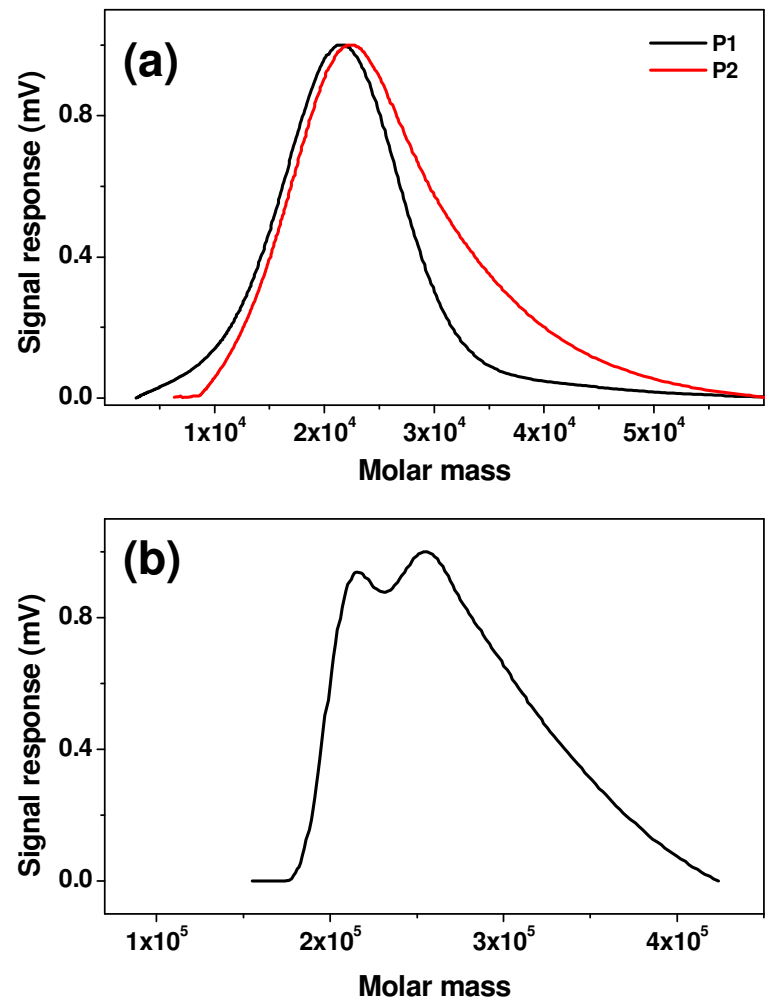

Figure S1. GPC chromatogram of (a) P1, P2 and (b) P3.

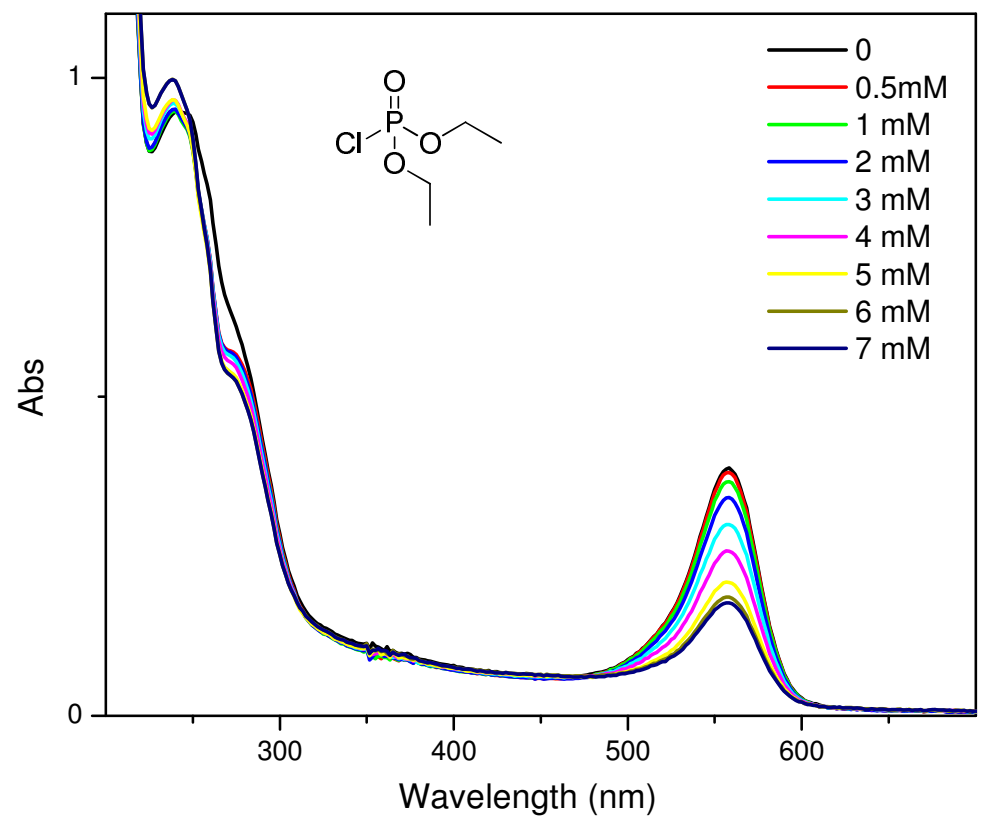

Figure S2. UV-Vis absorption spectra of P3 with various amounts of DCP in dioxane. 


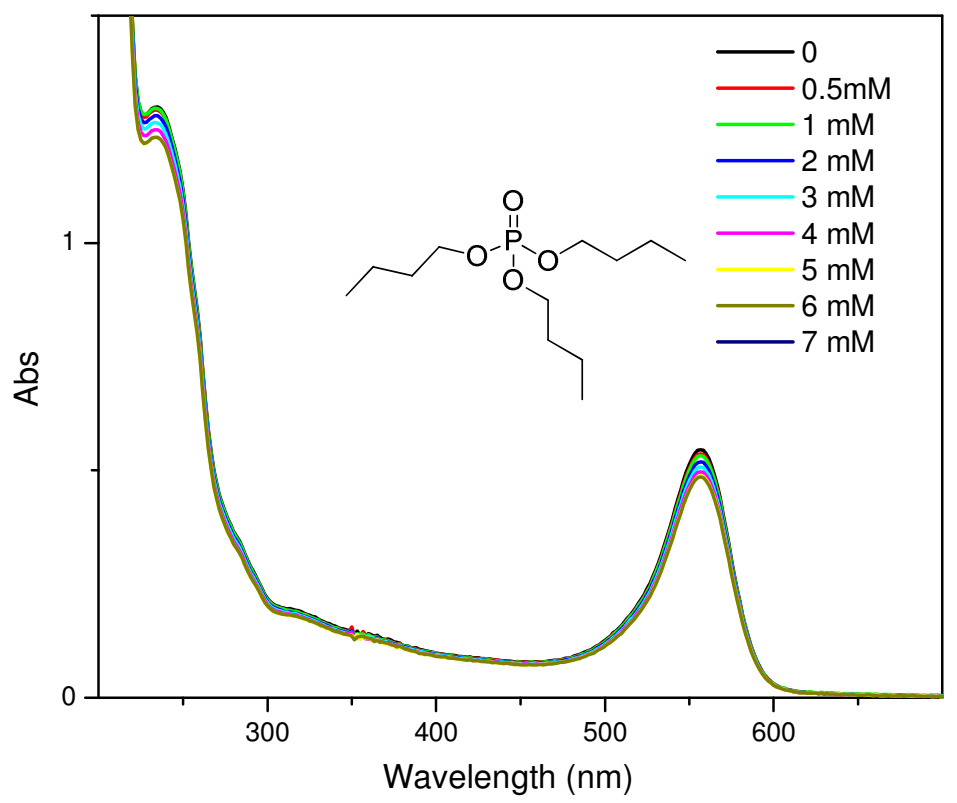

Figure S3. UV-Vis absorption spectra of P3 with various amounts of tributylphosphate (TBP) in dioxane.

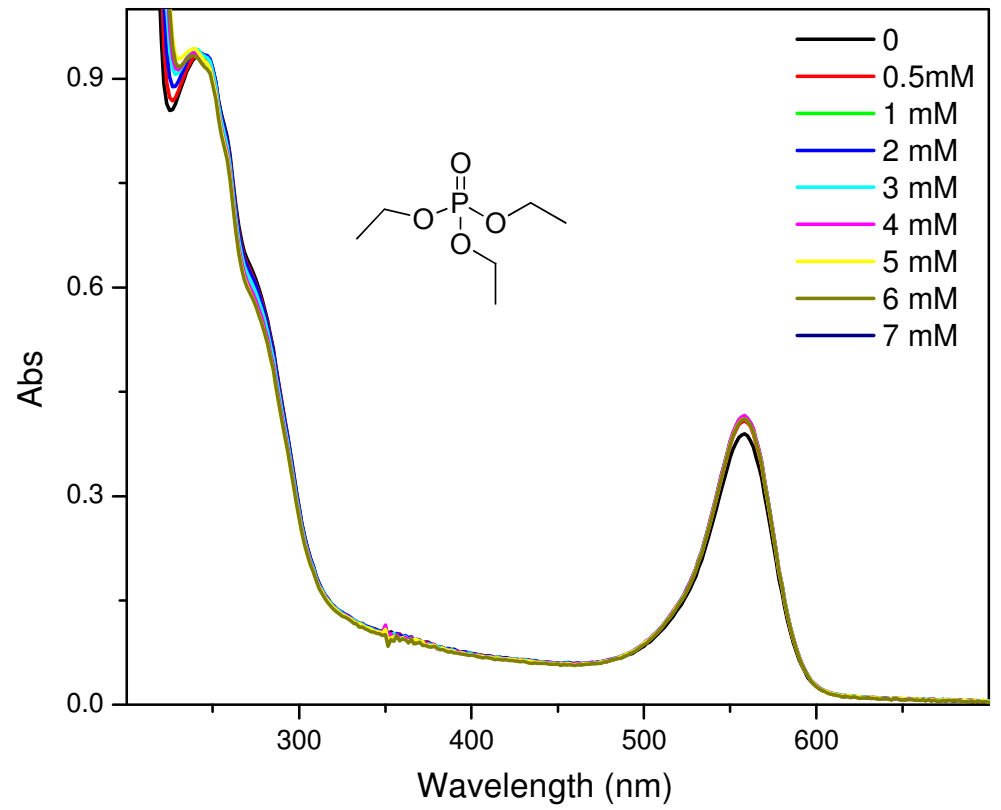

Figure S4. UV-Vis absorption spectra of P3 with various amounts of triethylphosphate (TEP) in dioxane. 


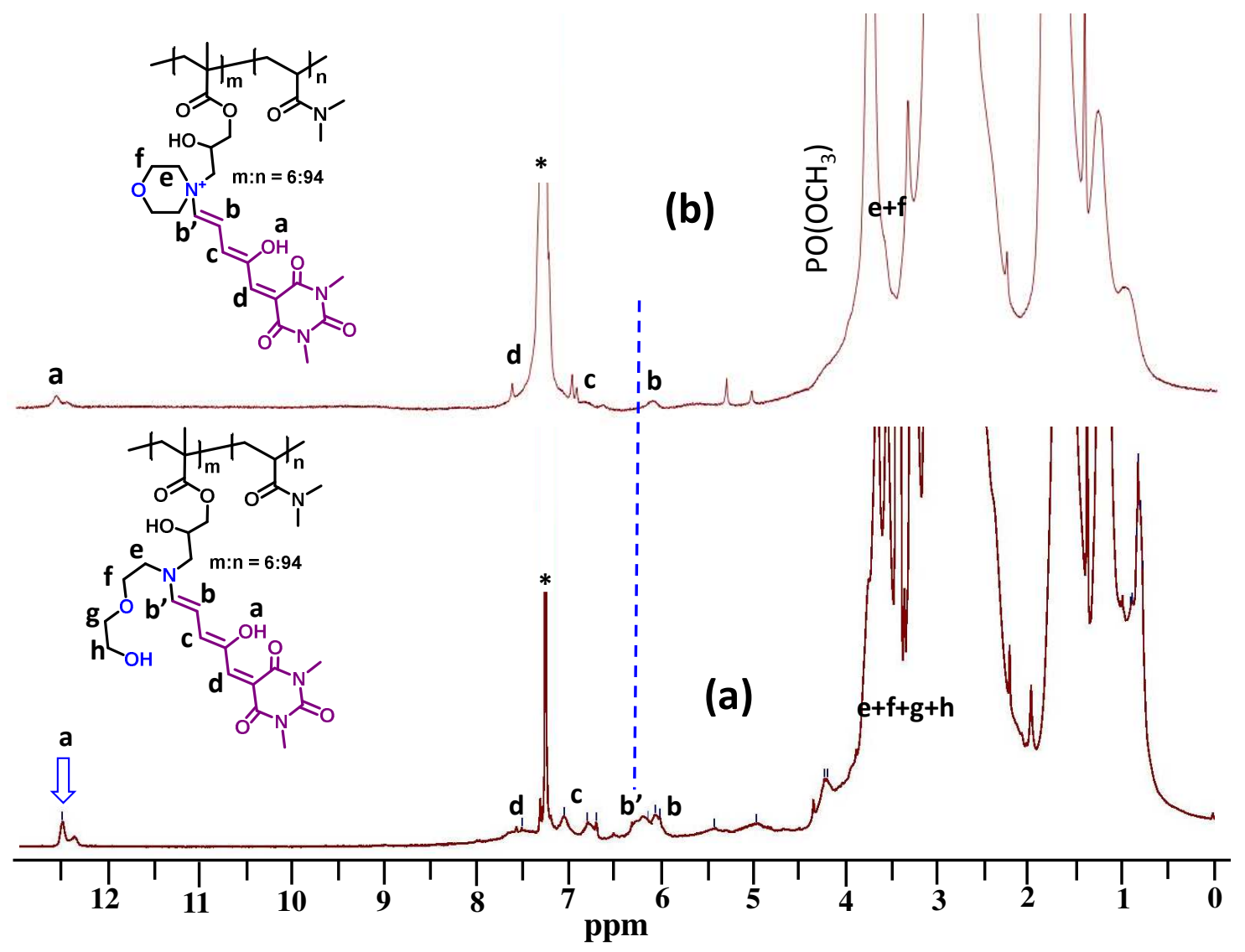

Figure S5. ${ }^{1} \mathrm{H}$ NMR spectra of DASA-derived polymeric probe P3 a) before and after addition of DCNP. 